\title{
Colorectal Cancer During Pregnancy-Case Report and Brief Review of The Literature
}

\author{
Faris Alaswad* and FRCS, FEBS, FICMS \\ Department of laporoscopic surgery, NMC Speciality hospital, Dubai \\ *Corresponding author: Faris Alaswad, Department of laporoscopic surgery, NMC Speciality hospital, Dubai
}

\begin{tabular}{|c|c|}
\hline ARTICLE INFO & ABSTRACT \\
\hline Received: 栔 October 02, 2019 & Abbreviations: CRC: Colorectal Cancer, ROM: Rupture of Membrane, LMP: Last Men- \\
\hline Published: 㓞October 09, 2019 & $\begin{array}{l}\text { strual Period, HB: Hemoglobin, LUQ: Left Upper Quadrant, LDH: Lactate Dehydrogenase, } \\
\text { CT: Computed Tomography }\end{array}$ \\
\hline
\end{tabular}

Citation: Faris Alaswad, Frcs Febs. Colorectal Cancer During PregnancyCase Report and Brief Review of The Literature. Biomed J Sci \& Tech Res 21(5)2019. BJSTR. MS.ID.003661.

\section{Introduction}

\section{Background}

Colorectal Cancer (CRC) in pregnancy is a condition that represents a distinct entity from CRC in the general population, as it is a rare pathology with limited high-grade evidence available for guidance. The diagnosis of CRC in pregnant women is usually delayed, because there is a significant overlap in signs and symptoms between a colorectal malignancy and normal pregnancy, impeding proper diagnosis. Once diagnosis is made, challenges exist as treatment options may be limited. That is why management requires judiciously individualized strategies after thorough patient counseling to deal with con-sequent emotional and physical stress, in order to ensure adequate psychological support and realistic expectations. Here, we present a case of colorectal cancer who was missed by pregnancy all over the pregnancy period and even the labor time.

\section{Case Report}

The patient was a 34-year-old woman who was referred with the complaints of vaginal discharge and suspicious Rupture of Membrane (ROM). The patient was not aware of her Last Menstrual Period (LMP) and had not any previous sonography result at that time to define gestational age, but she believed that only 5 days remained to the determined date for her elective cesarean section. There was not any remarkable point in her history and the patient did not mention any positive family history of cancer when she was asked. Physical examination revealed neither vaginal bleeding nor decreased fetal movement. The patient was overweight (BMI $=40 \mathrm{Kg} / \mathrm{m} 2$ ) and the vaginal examination was not possible due to intolerable pain, thus underwent spinal anesthesia for vaginal examination which revealed a dilation of two fingers, effacement about 30\%. Initial laboratory examination showed anemia with Hemoglobin ( $\mathrm{Hb}$ ) of $8 \mathrm{~g} / \mathrm{dL}$ and hematocrit of $24 \%$. She underwent emergency cesarean section.

During surgery there were lots of adhesions surrounding uterus, bladder, and abdominal wall which were attributed to the previous cesarean sections. Postoperatively, the patient was in a good condition without fever and bleeding and was discharged with medical and hygiene instructions. One week after surgery, the patient referred for checkup and removing of the sutures and there was no abnormality except being pallor, thus iron tablet was prescribed. One month after surgery, the patient presented with abdominal pain in the Left Upper Quadrant (LUQ). she was severely pale and there was a severe tenderness in LUQ. Physical examination shows a mass approximately $5 \times 6 \mathrm{~cm}$ in the LUQ. Abdominal plain Xray was normal without evidence of remained surgical tools. Abdominopelvic sonography showed a hypoechoic 20x25mm mass in the epigastric region anterior to the anteroinferior part of pancreas with fluid concentration and hematoma. Intestinal wall thickness in spleen curvature of the colon was noticed, the patient 
was transferred to a general surgery ward for further management. Examination showed severe anemia ( $\mathrm{Hb}: 5.1 \mathrm{~g} / \mathrm{dL})$ with raised erythrocyte sedimentation rate (ESR) (73). Other laboratory studies including Complete Blood Count (CBC), coagulation tests, electrolytes, Blood Urea Nitrogen (BUN), creatinine, Lactate Dehydrogenase (LDH), and indirect coombs were normal or within a normal range. The patient received 7 unite of packed blood cell and $\mathrm{Hb}$ levels rose to $11 \mathrm{~g} / \mathrm{dL}$. Computed Tomography (CT) scan confirmed a mass in LUQ and noted colon changes due to probable surgical complications of recent cesarean section. It was a long time since the surgery and this hypothesis was not acceptable by surgeons. Therefore, patient underwent colonoscopy which showed a mass in a spleen curvature of colon.

Patient shifted to the oncology ward and underwent partial colectomy of transverse colon $(20 \mathrm{~cm})$. Postoperative histopathologic study revealed a $5 \times 6 \times 7 \mathrm{~cm}$ mass in transverse colon. The tumor was sharp, extended up to the serosa (T3), without vascular, perineuronal, and lymphoma invasion. None of the 6 removed lymph nodes were involved. Both Proximal and distal margins were free of tumors. The tumor should be at least at stage IIa of the Duck class (T3, N0, Mx). Postoperative reevaluation of the patient revealed that the patient had similar transient abdominal pain since the start of her last pregnancy and was admitted with the impression of threatened miscarriage. She was treated and discharged with decrease in pain intensity. Pains existed all over the pregnancy and were attributed to the pregnancy, previous adhesion, and her obesity. More excitingly, after colonoscopy the patient mentioned that her mother had colon cancer and died due to this reason at age of 60-yearold. At the first interview and all over her previous medical records, this important history was not mentioned for unknown reason. After surgery, the patient underwent adjuvant chemotherapy and she became healthy without any problem 9 months after her surgery.

\section{Discussion}

Despite the low incidence rate of $0.07 \%$ to $0.1 \%$ [1-5], cancer accounts as a leading cause of death in women in childbearing ages [6]. CRC is among the eight most common malignancies in pregnancy [7]. Although its incidence is rare, it is associated with serious consequences for both the mother and even the fetus [8]. Its clinical manifestation, diagnosis, and treatment options seem a big challenge in front of treating physicians [9-13]. In some cases, it is possible only to save one life between the mother and the fetus which demands a deep ethical consideration and religious challenges. Our patient had experienced an intermittent abdominal pain all over her pregnancy with moderate anemia. Common presentations of CRC including abdominal pain, nausea, vomiting, anemia, and rectal bleeding usually masked by pregnancy and it is truly hard to distinguish these symptoms of what is considered as warning signs of CRC [2, 3-14]. This delay would lead to late diagnosis of the disease and subsequently poor prognosis. A majority of CRC cases in pregnancy present with Duck class C (44\%) in which adjutant therapies are needed to improve the surgical outcome [15].

In our case, appropriate clinical approach to abdominal pain or anemia would help to reach diagnosis. There are limitations to use most of the diagnostic imaging modalities during pregnancy; however, some can be used in specific circumstances. Colonoscopy which is routinely used in nonpregnant women is relatively contraindicated due to the potential mother and fetus risks and also fetal exposure to potential teratogens [16] and only should be performed with cautions. Due to radiation exposure, abdominal CT scan is not recommended specially in the first trimester $[7,8,9]$. Alternatively, ultrasonography and magnetic resonance imaging (MRI) could be applied; however, the sensitivity of sonography for detection of micrometastasis is not as high as CT imaging and MRI risks are not fully understood in pregnancy $[10,11]$. The main pathogenesis of CRC in pregnancy is still associated with lots of unanswered questions. Some factors including pregnancy hormones, the enzyme cyclocoxygenase-2 (Cox-2), and tumor suppressor protein p53 mentioned to be associated with CRC.

Most CRC cases have been found to be positive for estrogen (20-54\%) [7] and progesterone receptors (10-100\%) [1]. Maybe the increased levels of estrogen and progesterone during pregnancy stimulate the growth of tumoral cells with such receptors; however, all reports did not support this hypothesis. Slattery et al. in a study found only one case with positive progesterone receptor among 156 pregnant cases with CRC [2-11]. The elevated amounts of Cox2 in CRC patients has raised the hypothesis of its association with colorectal cancer; however, there are little evidences to elucidate its carcinogenic role. These probable genes were not analyzed in our patient. Colorectal cancer mostly involves elderly patients and its occurrence in young ages is rare; indeed, there may be some predisposing factors in such patients of significance in our patient was the family history of CRC. She was not aware of the importance of this issue in her recent problem. she stated this history after colonoscopy. The lack of general population knowledge in the society and inexistence of an organized screening program even for the most common leading cause of cancer-related deaths is an emergent public health concern for developing countries like UAE $[3,4,7]$. Gestational age and tumor stage are important to select treatment modality.

If tumor is resectable, surgical excision is recommended especially in those diagnosed in early pregnancy (before 20 weeks of gestation). In cases of later diagnosis, surgery can be postponed at the earlier possible date at which fetus can be viable (around 32 weeks). In advanced stages, when adjuvant therapy is needed, elective abortion would help to save mother's life, whilst in greater gestational ages it is possible to pursue adjuvant therapy after early delivery. It is important that the mother be fully informed of possible risks of each choice prior to her decision. In religious countries like UAE, there is another extra challenge for parents and clinician, since 
due to religious beliefs the legal abortion is only permitted up to the week 16 and after this time there would be problems to perform the abortion legally. CRC is associated with poor prognosis. The median survival in a review of pregnant patients with CRC was less than 5 months. Our patient underwent adjuvant chemotherapy and she became healthy without any problem 9 months after surgery.

\section{Conclusion}

The coexistence of malignant tumor and pregnancy is a state of simultaneous occurrence of two completely contra-dictory phenomena the development of a new life and a life-threatening terminal illness. In fact, CRC is an aggressive cancer that is rarely found during pregnancy, but when it appears it is expected poor outcome, as its usually diagnosed in late stages $[6,12,13]$. Because there are no absolute guidelines, it is associated with diagnostic and therapeutic challenges [12,13] as gravidity requires further quick and adequate diagnosis [3]. There is necessary further investigations about diagnostic and treatment modalities with reduced foetal side effects, in order to diminish its incidence and mortality rate [1]. Follow-upof the infants in later childhood and adolescence as the central nervous system continue to develop, with additional reporting of cases, is needed to establish the safety of chemotherapeutic treatment of CRC during pregnancy [16].

In fact, treatment during pregnancy varies widely and poses significant legal, ethical, religious, emotional and scientific challenges; therapy should be individualized and defined by a multidisciplinary team [2] that considers not only through patient counseling, but also the best management for both the patient and her foetus [2]. All the professionals who look after such a special patient should inform her considering the most current and reliable knowledge, providing her a multidisciplinary care, and understanding the complexity of coexistence of cancer and pregnancy. The patient should have the opportunity to decide about the fate of her pregnancy and it should not be affected by the moral beliefs of the doctor; the final decision concerns only to the patient. $[1,2,6]$ Above all, the treatment strategy for CRC should be no different for pregnant and non-pregnant patients in terms of the aim, which is potential curative treatment of the disease, but should always consider the patient's conscious decision on pregnancy further management.

\section{ISSN: 2574-1241}

DOI: 10.26717/BJSTR.2019.21.00361

Faris Alaswad. Biomed J Sci \& Tech Res

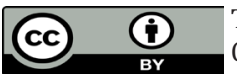

This work is licensed under Creative Commons Attribution 4.0 License

Submission Link: https://biomedres.us/submit-manuscript.php

\section{References}

1. Kraljevic M, Hoffmann H, Knipprath A, Von Holzen U (2014) Obstructing adenocarcinoma of the descending colon in a31-year-old pregnant woman. Int J Surg Case Rep 5(12): 958-960.

2. Yaghoobi M, Koren G, Nulman I (2009) Challenges to diagnosing colorectal cancer during pregnancy. Can Fam Physician 55(9): 881-885.

3. Khangura RK, Khangura CK, Desai A, Goyert G, Sangha R (2015) Metastatic colorectal cancer resembling severe preeclampsiain pregnancy. Case Rep Obstet Gynecol 487824.

4. Gabriel I, Olejek A, Drozdzowska B (2016) Colon cancer in pregnancy-a difficult diagnosis. Eur J Obstet Gynecol Reprod Biol 203: 340-341.

5. Dahling MT, Xing G, Cress R, Danielsen B, Smith LH (2009) Pregnancyassociated colon and rectal cancer: perinatal andcancer outcomes. J Matern Fetal Neonatal Med 22(3): 204-211.

6. Haggar F, Pereira G, Preen D, Woods J, Martel G, et al. (2013) Maternal and neonatal outcomes in pregnancies following colorectal cancer. Surg Endosc 27(7): 2327-2336.

7. Robson DE, Lewin J, Cheng AW, ORourke NA, Cavallucci DJ (2015) Synchronous colorectal liver metastases in pregnancy andpost-partum: SCRLMS in pregnancy and post-partum. ANZ JSurg 87(10): 800-804.

8. Okuda T, Ishii H, Yamashita S, Ijichi S, Matsuo S, et al. (2015) Rectal cancer diagnosed after cesarean section in whichhigh microsatellite instability indicated the presence of Lynchsyndrome. Case Rep Obstet Gynecol.

9. Longo SA, Moore RC, Canzoneri BJ, Robichaux A (2010) Gastrointestinal conditions during pregnancy. Clin Colon Rectal Surg 23(2): 80-89.

10. Toosi M, Moaddabshoar L, Malek Hosseini SA, Sasani MR, Mokhtari M, et al. (2014) cancer in pregnancy: a diagnostic and therapeutic challenge. J Egypt Natl Cancer Inst 26(1): 175-179.

11. Dhull AK, Gogia P, Atri R, Dhankhar R, Kaushal V, et al. (2015) Exploring signet-ring cells in pregnant female. JGastrointest Oncol 6(5): E10-15.

12. Basta P, Bak A, Roszkowski K (2015) Cancer treatment in pregnant Women. Contemp Oncol 19(5): 354-360.

13. Makoshi Z, Perrott C, Al Khatani K, Al Mohaisen F (2015) Chemotherapeutic treatment of colorectal cancer inpregnancy: case report. J Med Case Rep 13(9): 140.

14. Mechery J, Ikhena SE (2007) Cancer of the descending colon during pregnancy. J Obstet Gynaecol 27(3): 311-312.

15. Vasen HFA, Moslein G, Alonso A, Bernstein I, Bertario L, et al. (2007) Guidelines for the clinical management ofLynch syndrome (hereditary non- polyposis cancer). J MedGenet. 44(6): 353-362.

16. Lynch HT, Lynch JF, Attard TA (2009) Diagnosis and management ofhereditary colorectal cancer syndromes: Lynch syndrome as amodel. Can Med Assoc J 181(5): 2734205.

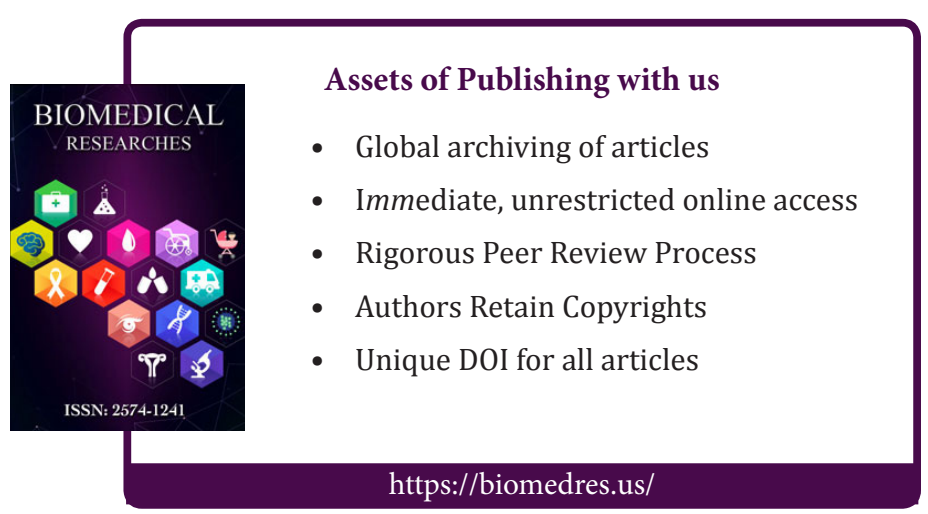

Copyright@ Faris Alaswad | Biomed J Sci \& Tech Res | BJSTR. MS.ID.003660. 